\title{
Effect of Pipe Diameter on Electrochemical Behavior of Stainless Steel Type 304 Pipes in Tap Water
}

\author{
Noriyuki Tanaka1 ${ }^{*}$, Shigeru Sato ${ }^{1}$, Itaru Ikeda ${ }^{2}$, Tadahiko Uchida², Motoki Kuratani2, \\ Yutaka Yamada ${ }^{2}$, Osamu Sakurada ${ }^{2}$ \\ ${ }^{1}$ Technical Research Laboratory, DAI-DAN Co., Ltd., Saitama, Japan \\ ${ }^{2}$ Gifu University, Gifu, Japan \\ Email: *tanakanoriyuki@daidan.co.jp, satosh igeru@daidan.co.jp, x452401 0@edu.gifu-u.ac.jp, x4524019@edu.gifu-u.ac.jp, \\ v3032069@edu.gifu-u.ac.jp,y_yamada@gifu-u.ac.jp, sakurada@gifu-u.ac.jp
}

How to cite this paper: Tanaka, N., Sato, S., Ikeda, I., Uchida, T., Kuratani, M., Yamada, Y. and Sakurada, O. (2019) Effect of Pipe Diameter on Electrochemical Behavior of Stainless Steel Type 304 Pipes in Tap Water. Materials Sciences and Applications, 10, 697-708.

https://doi.org/10.4236/msa.2019.1011050

Received: October 3, 2019

Accepted: November 15, 2019

Published: November 18, 2019

Copyright $\odot 2019$ by author(s) and Scientific Research Publishing Inc. This work is licensed under the Creative Commons Attribution International License (CC BY 4.0).

http://creativecommons.org/licenses/by/4.0/

(c) (i) Open Access

\begin{abstract}
We investigated the effects of pipe diameter on the corrosion resistance of stainless steel type 304 pipes using electrochemical measurements. Compared to plate steel, pipes have harder physical properties and tend to be harder and showed greater permeability with decreasing inner diameter. We found that the maximum corrosion current density in the secondary active state, which is the starting point of secondary passivation, appeared in the polarization curve measurement in tap water. Similar to the Vickers hardness and the maximum current density in the secondary active state, the permeability tended to increase as the diameter decreased. This is thought to increase the amount of deformation-induced martensitic and increase corrosion susceptibility. The peak of the secondary active current density was clearly seen as the potential sweep speed was increased. In addition, potential sweep speed dependence was observed in the corrosion susceptibility evaluation of deformation-induced martensite. In comparison with acid treatment, the formation of deformation-induced martensite was considered to occur in the extreme surface layer. The maximum corrosion current density in the secondary active state is expected to be a new susceptibility evaluation method for evaluating the deformation-induced martensitic transformation.
\end{abstract}

\section{Keywords}

Stainless Steel Type 304, Electrochemical Consideration, Pipe Diameter, Electrochemical Behavior, Tap Water

\section{Introduction}

Previously, we reported the results of a corrosion case study of stainless steel 
type 304 pipes used for circulated hot water supply piping and the results of circulated corrosion tests simulating an actual environment [1] [2]. Corrosion case studies showed that localized corrosion occurred in straight pipes with an inner diameter $<50 \mathrm{~mm}$ and in environments with a residual chlorine concentration $<$ $0.4 \mathrm{mg} / \mathrm{L}$. In the circulating corrosion test, observed film destruction, which was considered to be a sign of localized corrosion, at residual chlorine concentration exceeded $0.3 \mathrm{mg} / \mathrm{L}$ for both steel plate and pipes. From the results of the corrosion case study and circulation test, we considered that the film breakdown potential of stainless steel type 304 was around $0.4 \mathrm{~V}$ vs. $\mathrm{Ag} / \mathrm{AgCl}$ reference electrode (SSE). In addition, the straight pipe had a higher inner surface Vickers hardness than the steel plate, and tended to become harder as the inner diameter decreased. From the results of this Vickers hardness measurement, it was considered that the corrosion sensitivity increased due to the deformation-induced martensitic with smaller inner diameter [3]-[10]. In this study, we investigated the effects of pipe diameter on the polarization behavior using anodic polarization curve measurements.

\section{Method}

\subsection{Test Materials}

The test materials consisted of stainless steel type 304 produced from cold-rolled stainless steel plate sheet (JIS G 4305, hereafter referred to as "plate") $50 \mathrm{~mm}$ in length $\times 30 \mathrm{~mm}$ in width $\times 0.8 \mathrm{~mm}$ wall thickness, and stainless steel type 304 of light gauge stainless steel tubes for ordinary piping (JIS G 3448) $13 \mathrm{~mm}$ in inner diameter $\times 15.88 \mathrm{~mm}$ in outside diameter $\times 0.8 \mathrm{~mm}$ wall thickness $\times 150 \mathrm{~mm}$ in length (hereafter referred to as pipe $13 \mathrm{~mm}$ ), $25 \mathrm{~mm}$ in inner diameter $\times 25.58$ $\mathrm{mm}$ in outside diameter $\times 1.0 \mathrm{~mm}$ wall thickness $\times 150 \mathrm{~mm}$ in length (hereafter referred to as pipe $25 \mathrm{~mm}$ ), $50 \mathrm{~mm}$ in inner diameter $\times 48.60 \mathrm{~mm}$ in outside diameter $\times 1.2 \mathrm{~mm}$ wall thickness $\times 150 \mathrm{~mm}$ in length (hereafter referred to as pipe $50 \mathrm{~mm}$ ). Table 1 shows the chemical compositions of the specimens used. The test materials were obtained from commercial sources. All test materials were subjected to degreasing only without surface scrubbing prior to use in the experiments. In addition, all specimens left a $1 \mathrm{~cm}^{2}$ corner as an effective area and coating processed the whole. Specimens treated with acid using a mixture of gelled nitric acid and hydrofluoric acid were also used.

\subsection{Test Equipment}

Figure 1 shows a schematic diagram of the polarization curve measurement equipment. The test water used was the same as that used in the previous study [1]. Briefly, $500 \mathrm{~mL}$ of test water was placed in a 1-L cell container with a lid, and the polarization curves of each test material were measured at room temperature. The measurements were performed while stirring at a speed of $300 \mathrm{rpm}$. The anode polarization curve was measured by deoxidizing the test solution with nitrogen gas, and the cathode polarization curve was measured open to the 
Table 1. Chemical compositions of the specimens used.

\begin{tabular}{ccccccccccc}
\hline Specimen & $\mathrm{C}$ & $\mathrm{Si}$ & $\mathrm{Mn}$ & $\mathrm{P}$ & $\mathrm{S}$ & $\mathrm{Ni}$ & $\mathrm{Cr}$ & $\mathrm{Mo}$ & $\mathrm{Cu}$ & $\mathrm{N}$ \\
\hline pipe $13 \mathrm{~mm}$ & 0.036 & 0.37 & 1.05 & 0.033 & 0.005 & 8.07 & 18.22 & 0.14 & 0.31 & 0.039 \\
pipe $25 \mathrm{~mm}$ & 0.051 & 0.46 & 1.04 & 0.032 & 0.002 & 8.06 & 18.28 & 0.12 & 0.31 & 0.036 \\
pipe $50 \mathrm{~mm}$ & 0.043 & 0.39 & 1.04 & 0.029 & 0.002 & 8.05 & 18.02 & 0.07 & 0.21 & 0.041 \\
Plate & 0.057 & 0.34 & 1.06 & 0.032 & 0.004 & 8.09 & 18.07 & 0.15 & 0.36 & 0.035 \\
\hline
\end{tabular}

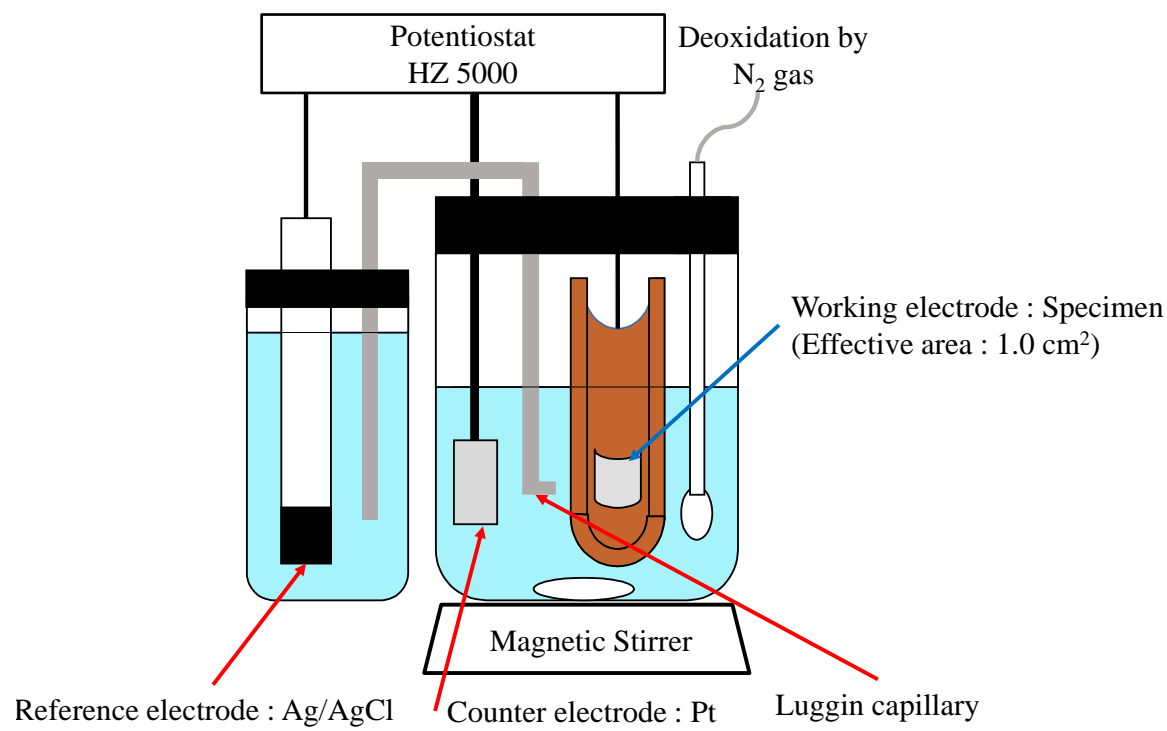

Figure 1. Schematic diagram of polarization curve measurement equipment.

atmosphere. The working electrode was the test material, the reference electrode was an $\mathrm{Ag} / \mathrm{AgCl}$ electrode (SSE), and the counter electrode was platinum. Polarization curve measurement was measured three times for each material using a potentiostat (HZ-5000; Hokuto Denko) using the potentiodynamic method with sweep speeds of 10,50 , and $100 \mathrm{mV} / \mathrm{min}$.

\subsection{Test Condition}

Table 2 shows the test conditions, and Table 3 shows the results of water quality analysis for the tap water in Miyoshi-machi, Iruma-gun, Saitama. Tap water of $\mathrm{pH} 7.6$ shown in Table 3 was used as the test water, and the $\mathrm{pH}$ was also adjusted with carbon dioxide gas to $\mathrm{pH} 6.0$ and 7.0. The chloride ion concentration of test water was adjusted to a chloride ion concentration of $16 \mathrm{mg} / \mathrm{L}$ in tap water and $50 \mathrm{mg} / \mathrm{L}$ and $100 \mathrm{mg} / \mathrm{L}$ using sodium chloride. Polarization curve measurement was measured three times for each material using a potentiostat (HZ-5000; Hokuto Denko) using the potentiodynamic method with sweep speeds of 10,50 , and $100 \mathrm{mV} / \mathrm{min}$.

\section{Results and Discussion}

\subsection{Anodic Polarization Curve in Raw Water}

Figure 2 shows the measurement results of the anodic polarization curve of each 
Table 2. Test conditions.

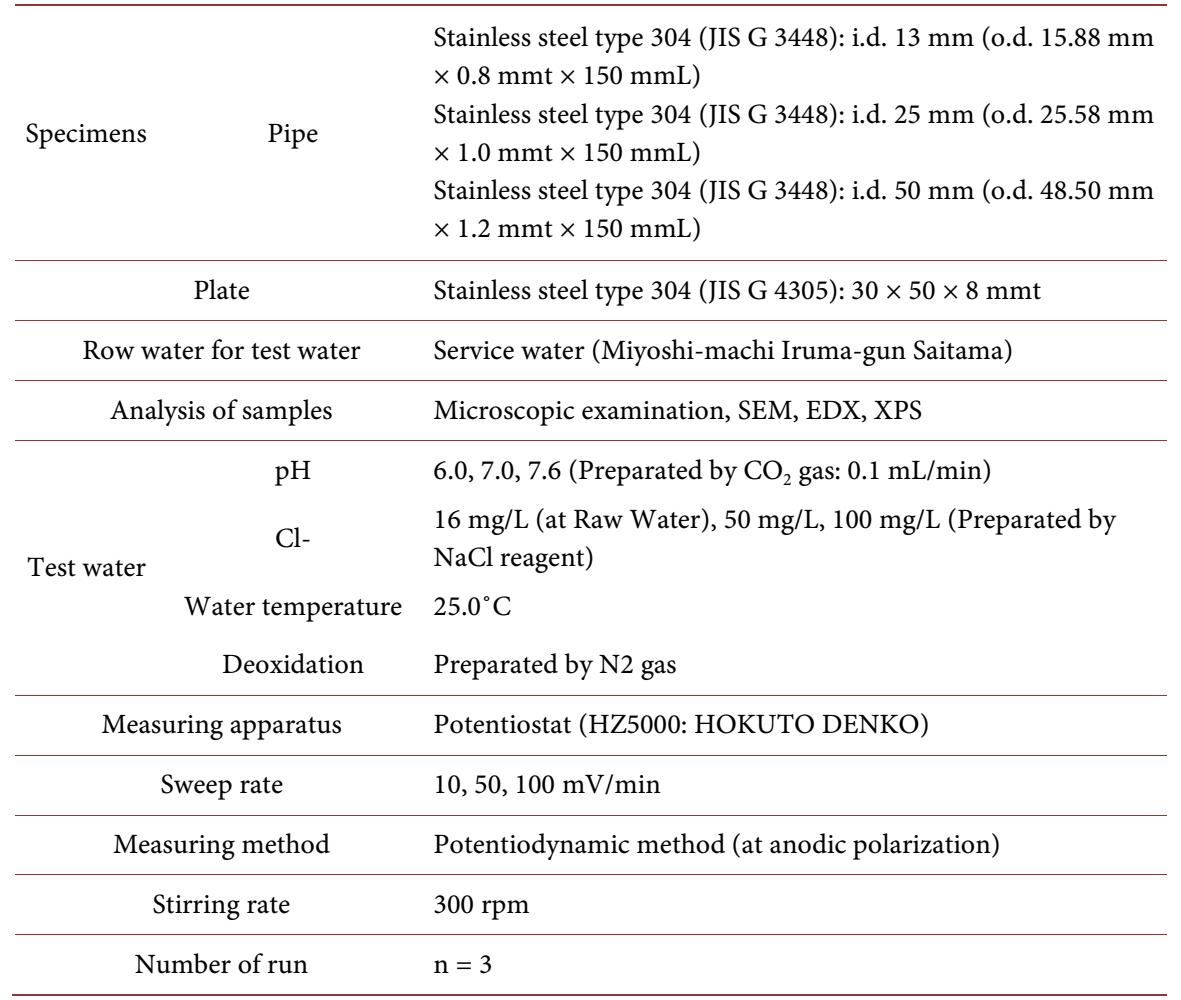

Table 3. Chemical analysis of test water.

\begin{tabular}{ccc}
\hline \multicolumn{2}{c}{ Quality of Water Item } & Results \\
\hline $\mathrm{pH}$ & {$[-]$} & 7.6 \\
Electric Conductivity & {$[\mathrm{mS} / \mathrm{m}]$} & 21.9 \\
Acid Consumption $(\mathrm{Ph} 4.8)$ & {$\left[\mathrm{mgCaCO}_{3} / \mathrm{L}\right]$} & 51 \\
$\mathrm{Cl}^{-}$ & {$[\mathrm{mg} / \mathrm{L}]$} & 16 \\
$\mathrm{SO}_{4}^{2-}$ & {$[\mathrm{mg} / \mathrm{L}]$} & 23 \\
$\mathrm{Total}_{\mathrm{Hardness}}^{2-}$ & {$\left[\mathrm{mgCaCO}_{3} / \mathrm{L}\right]$} & 77 \\
$\mathrm{Calcium} \mathrm{Hardness}$ & {$[\mathrm{mgCaCO} / \mathrm{L}]$} & 56 \\
$\mathrm{SiO}_{2}$ & {$[\mathrm{mg} / \mathrm{L}]$} & 25 \\
$\mathrm{Fe}$ & {$[\mathrm{mg} / \mathrm{L}]$} & $<0.1$ \\
$\mathrm{Cu}$ & {$[\mathrm{mg} / \mathrm{L}]$} & $<0.1$ \\
\hline
\end{tabular}

specimen. The pipe $13 \mathrm{~mm}$, pipe $25 \mathrm{~mm}$, and pipe $50 \mathrm{~mm}$ specimens excluding the plate showed stable current density from $-0.3 \mathrm{~V}$ vs. SSE to $+0.4 \mathrm{~V}$ vs. SSE. The current density increased rapidly from around $0.5 \mathrm{~V}$ vs. SSE, and reached a maximum near $+0.7 \mathrm{~V}$ vs. SSE. Subsequently, it decreased to $+1.0 \mathrm{~V}$ vs. SSE, reached a minimum, and then again showed a rapid rise. The stable region of the current density from $-0.3 \mathrm{~V}$ vs. SSE to $+0.4 \mathrm{~V}$ vs. SSE was defined as a passive state, and the rapid rise observed near $+0.5 \mathrm{~V}$ vs. SSE was defined as the corrosion potential. The rise from the $+0.5 \mathrm{~V}$ vs. SSE to $+0.7 \mathrm{~V}$ vs. SSE until the 


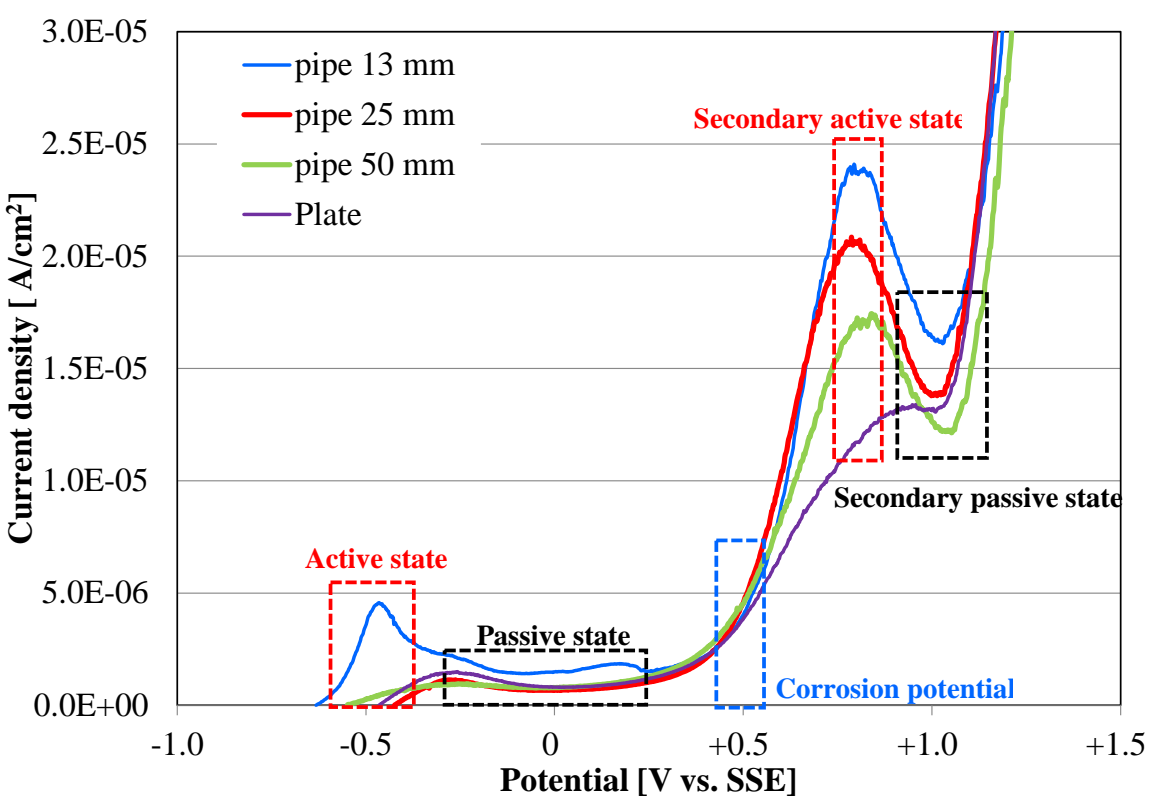

Figure 2. Comparison of polarization curves under conditions of $\mathrm{pH} 7.6$ and chlorine ionconcentration of $16 \mathrm{mg} / \mathrm{L}$ for each specimen.

maximum current density was obtained was defined as the secondary active state where the secondary passive state originated. Furthermore, the minimum of the current density near $+1.0 \mathrm{~V}$ vs. SSE was defined as the secondary passive state. The current density of pipe $13 \mathrm{~mm}$ rose from around $-0.6 \mathrm{~V}$ vs. SSE, and showed a maximum of $5.0 \times 10^{-6} \mathrm{~A} / \mathrm{cm}^{2}$ near $-0.5 \mathrm{~V}$ vs. SSE. It subsequently decreased to $1.0 \times 10^{-6} \mathrm{~A} / \mathrm{cm}^{2}$, showed a passive state, and reached the maximum current density of $2.4 \times 10^{-5} \mathrm{~A} / \mathrm{cm}^{2}$ in the secondary active state through the corrosion potential. It decreased to $1.7 \times 10^{-5} \mathrm{~A} / \mathrm{cm}^{2}$ by $+1.0 \mathrm{~V}$ vs. SSE, but continued to rise again. In pipe $25 \mathrm{~mm}$, the current density rose from around $-0.4 \mathrm{~V}$ vs. SSE and showed the passive state around $-0.3 \mathrm{~V}$ vs. SSE. The maximum current density subsequently reached $2.1 \times 10^{-5} \mathrm{~A} / \mathrm{cm}^{2}$ in the secondary active state through the pitting potential. It decreased to $1.4 \times 10^{-5} \mathrm{~A} / \mathrm{cm}^{2}$ by $1.0 \mathrm{~V}$ vs. SSE, but continued to rise again. In pipe $50 \mathrm{~mm}$, the current density rose from around $-0.5 \mathrm{~V}$ vs. SSE and showed a passive state around $-0.3 \mathrm{~V}$ vs. SSE. It subsequently reached $1.7 \times 10^{-5} \mathrm{~A} / \mathrm{cm}^{2}$ in the secondary active state through the corrosion potential. It decreased to $1.2 \times 10^{-5} \mathrm{~A} / \mathrm{cm}^{2}$ by $+1.0 \mathrm{~V}$ vs. SSE, but continued to increase again. In the plate, the current density rose from around -0.5 $\mathrm{V}$ vs. SSE, and in the vicinity of $-0.3 \mathrm{~V}$ vs. SSE, it showed a passive state in the same way as the other specimens. Subsequently, it reached $1.3 \times 10^{-5} \mathrm{~A} / \mathrm{cm}^{2}$ in the secondary active state through the corrosion potential. However, there was no subsequent decrease in current density as in the other specimens, and it remained at $1.3 \times 10^{-5} \mathrm{~A} / \mathrm{cm}^{2}$ up to $+1.0 \mathrm{~V}$ vs. SSE, and then continued to increase again. There was almost no difference in the current density between the passive state and the corrosion potential of each specimen. On the other hand, the maximum current density in the secondary active state tended to increase as the plate 
was the smallest and the pipe diameter became smaller. From the magnitude of current density, the effect of pipe bending on corrosion sensitivity was suggested. Therefore, the corrosion susceptibility was considered to increase with decreasing pipe diameter.

\subsection{Effect of $\mathrm{pH}$ on the Anodic Polarization Curve}

Figure 3 shows the anodic polarization curves according to $\mathrm{pH}$ at a chloride ion concentration of $16 \mathrm{mg} / \mathrm{L}$ for each test material. The anodic polarization curves under conditions of pH 6.0 and 7.0 for pipe $13 \mathrm{~mm}$, pipe $25 \mathrm{~mm}$, and pipe 50 $\mathrm{mm}$, excluding the plate, were similar to the results shown in Figure 2. The passive state up to $+0.4 \mathrm{~V}$ vs. SSE, corrosion potential near $+0.5 \mathrm{~V}$ vs. SSE, secondary active state near $+0.7 \mathrm{~V}$ vs. SSE, and secondary passive state was observed reaching the minimum current density up to $+1.0 \mathrm{~V}$ vs. SSE. Subsequently, the current density increased rapidly again. Figure 4 shows the current densities in the passive state and secondary active state from the anodic polarization curve of each specimen. At pH 7.6, the maximum current density, which is the origin of secondary passivation, generally decreased as the pipe diameter increased, and increased with decreasing $\mathrm{pH}$ as the pipe diameter decreased. From this pipe diameter and the behavior of the maximum current density, which is the starting point of the secondary passive state, it was considered that smaller pipe diameter and lower $\mathrm{pH}$ led to easier corrosion.

\subsection{Effect of Chloride Ion on the Anodic Polarization Curve}

Figure 5 shows the results of measurement of the anodic polarization curve of each specimen according to the chloride ion concentration. The secondary active state around $+0.7 \mathrm{~V}$ vs. SSE observed at a chloride ion concentration of $16 \mathrm{mg} / \mathrm{L}$ disappeared as the chloride ion concentration increased. There have been many reports on the corrosive effects of chloride ion concentration on stainless steel materials, but there have been no reports regarding the maximum current density in the secondary active state, which is the origin of the secondary passive
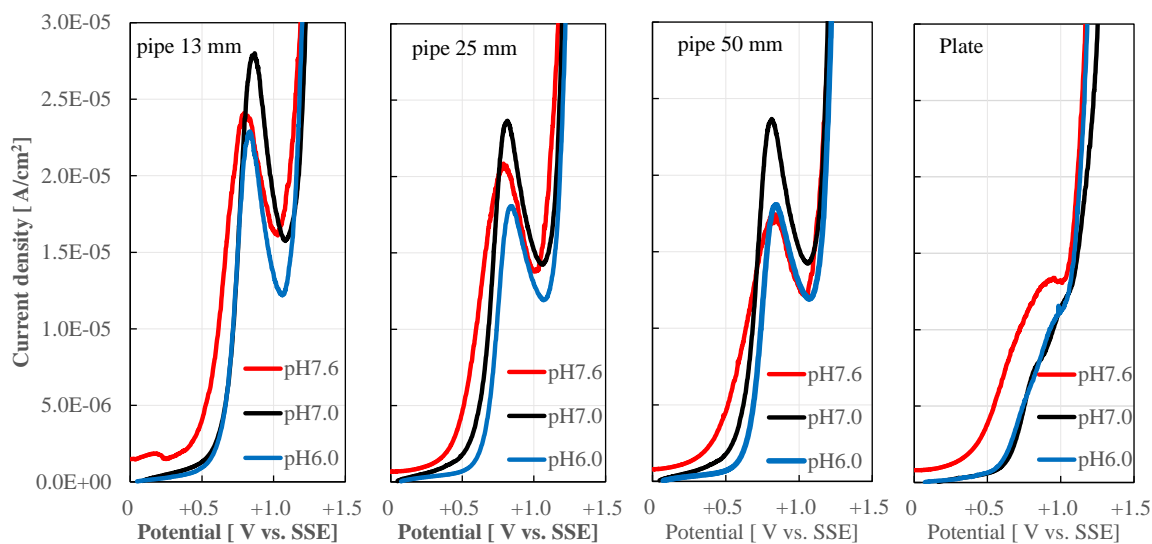

Figure 3. Effects of $\mathrm{pH}$ on polarization curve at a chlorine ion concentration of $16 \mathrm{mg} / \mathrm{L}$ for each specimen. 


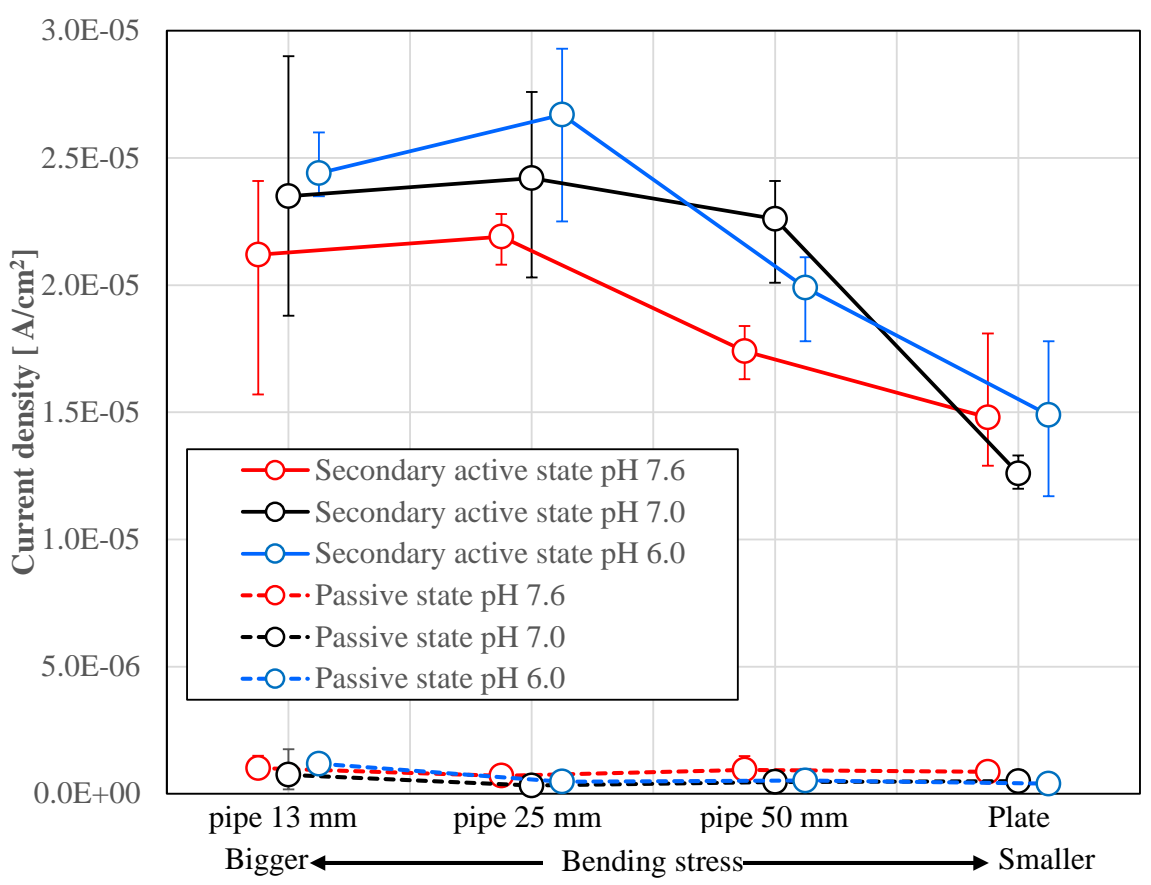

Figure 4. Comparison of current density in the passive state and secondary active state for each specimen at each $\mathrm{pH}$.
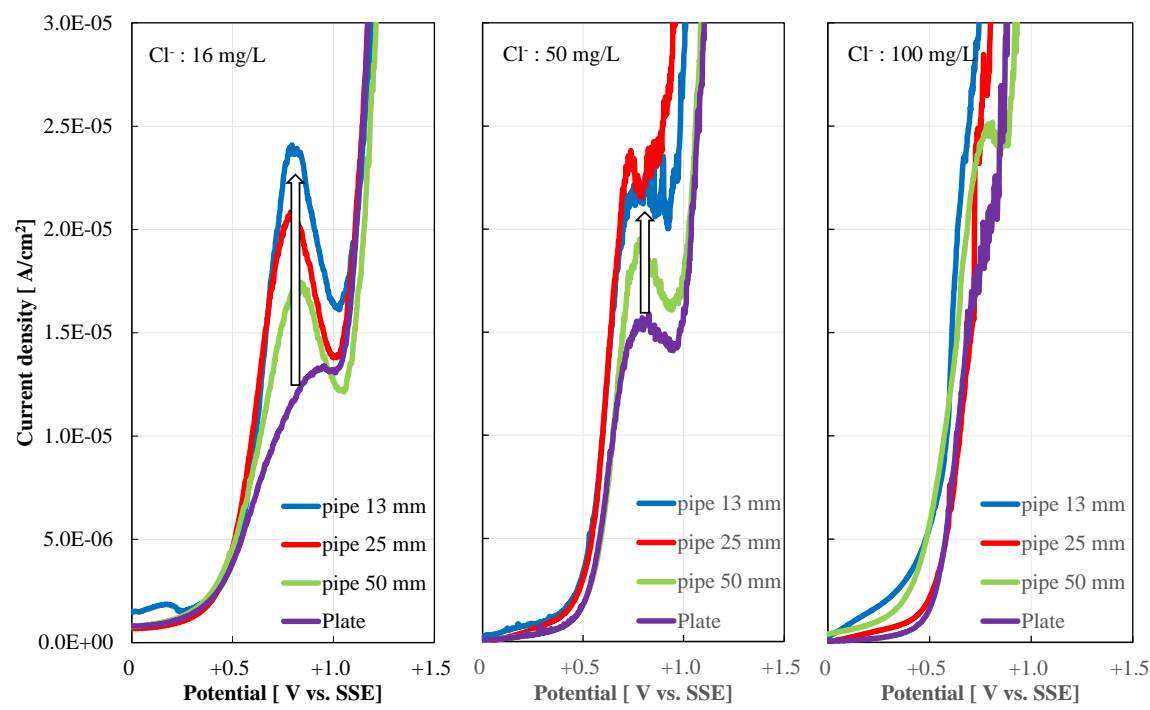

Figure 5. Effects of chlorine ionconcentration at $\mathrm{pH} 7.6$ for each specimen.

state observed in this case. This may be because previous studies were conducted under accelerated conditions with chloride ion concentrations $\geq 100 \mathrm{mg} / \mathrm{L}$. Analysis of the behavior of the anodic polarization curves confirmed the dependence of secondary passivity on the chloride ion concentration. This is probably because the surface layer of the metal is a film affected by the deformation-induced martensitic transformation. Figure 6 shows the results of X-ray photoelectron spectroscopy (XPS) analysis results of the plate in the passive and secondary active states observed in the anodic polarization curve measurement under 


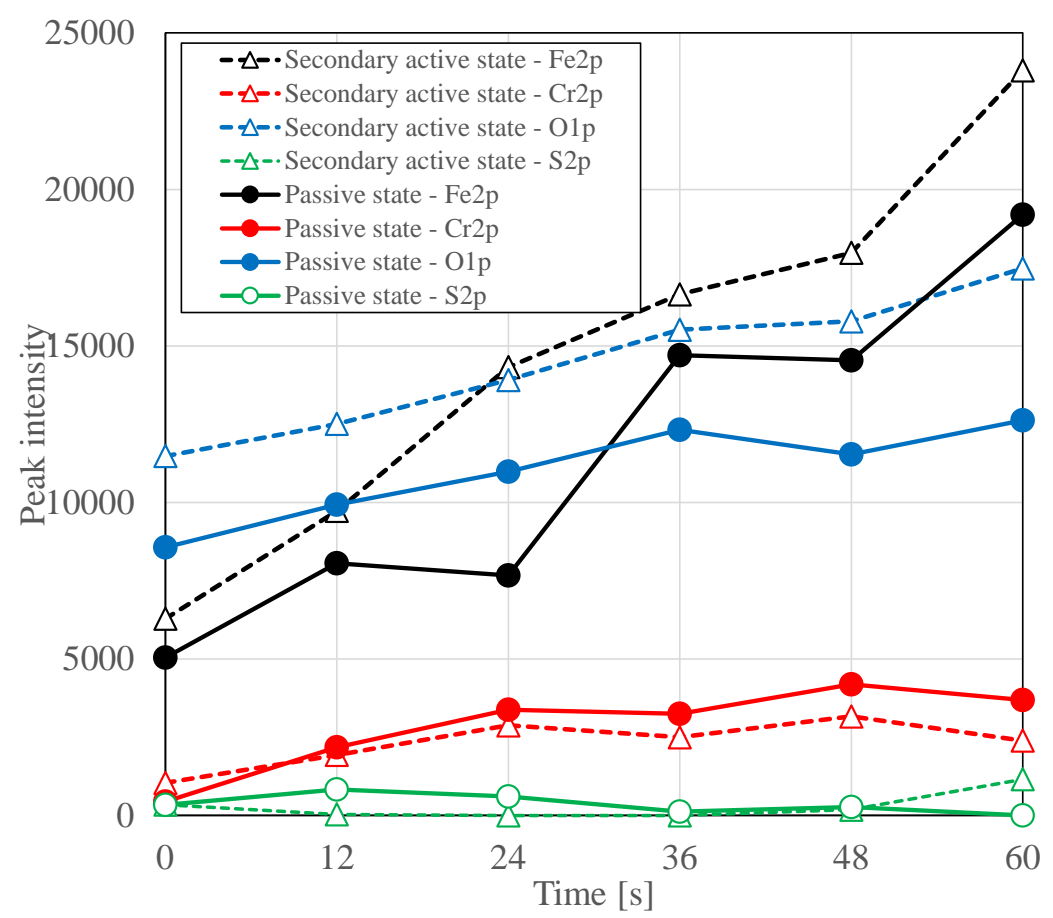

Figure 6. Results of XPS analysis of plate specimens after polarization curve measurement at $\mathrm{pH} 7.6$ and chlorine ion concentration of $16 \mathrm{mg} / \mathrm{L}$.

conditions of $\mathrm{pH} 7.6$ and chloride ion concentration of $16 \mathrm{mg} / \mathrm{L}$. The abundance of $\mathrm{Cr}$ in the secondary active state was decreased compared to the passive state, but the abundances of $\mathrm{Fe}$ and $\mathrm{O}$ in the secondary active state were increased. These results suggested that chromium oxide decreased, iron oxide increased, and the abundance ratio changed in the secondary active state compared to the passive state. From these results, it is considered that the passive film in the secondary active state has inferior corrosion resistance and is more susceptible to corrosion than in the passive state. Therefore, it disappears when the chloride ion concentration increases and the corrosion effect increases, making it impossible to observe.

\subsection{Effect of Sweep Speedand on the Anodic Polarization Curve}

Figure 7 shows an anodic polarization curve measured at various potential sweep speeds for pipe $13 \mathrm{~mm}$ without acid treatment, and Figure 8 shows that with 60-minute acid treatment. In the specimen without acid treatment shown in Figure 7 , the secondary active state potential decreased and the maximum current density tended to decrease as the potential sweep speed decreased and was hardly observed at $10 \mathrm{mV} / \mathrm{min}$. There was also a difference in the potential at which the current density increased rapidly thereafter. On the other hand, with 60-minute acid treatment as shown in Figure 8, the secondary active maximum current density did not change significantly, as in Figure 7, regardless of the potential sweep speed. The subsequent rapid increase in current density showed the same behavior as in Figure 7. The plate also behaved similarly to Figure 8. 




Figure 7. Anodic polarization curve of pipe $13 \mathrm{~mm}$ without acid treatment.

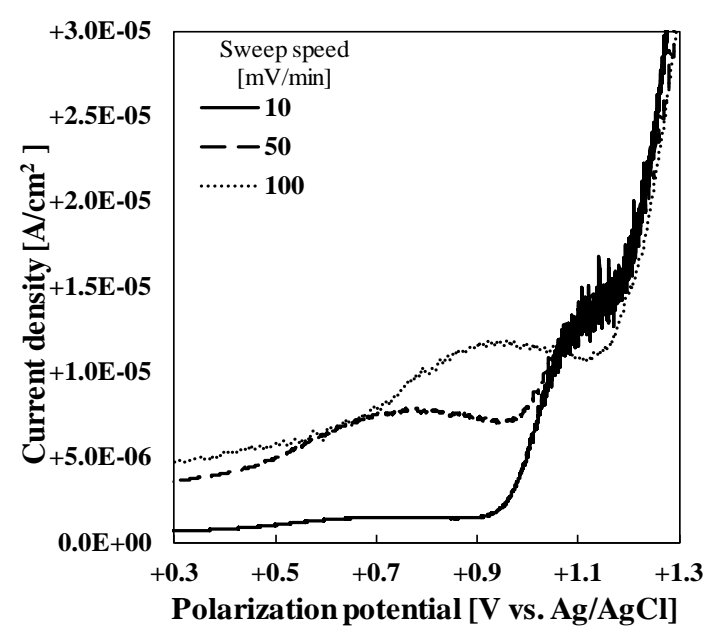

Figure 8. Anodic polarization curve of pipe $13 \mathrm{~mm}$ with acid treatment.

The secondary active state maximum current density decreased with decreasing potential sweep speed. It tended to disappear with acid treatment and there was also a difference in the maximum potential. In this case, when the potential sweep speed is high, the potential rise rate is greater than the dissolution reaction rate and the secondary active maximum current density occurs. However, in the slow case, the rate of potential rise $\fallingdotseq$ dissolution reaction rate and the secondary active maximum current density is unlikely to occur. As the secondary active state maximum current density disappeared in the results shown in Figure 8, the secondary active state maximum current density seen in Figure 7 was thought to be due to the formation of deformation-induced martensite.

\subsection{Examination of Deformation-Induced Martensitic Transformation Evaluation Method}

The existence of a maximum current density in the secondary active state, which 
is the starting point of the secondary passive state, is a novel finding that has not been reported previously. As the maximum current density is correlated with the pipe diameter, it can be expected to be applicable to methods for evaluating the corrosion susceptibility of stainless steel type 304 pipes in tap water environments.

Stainless steel type 304 is classified as austenitic stainless steel, and is known as a non-magnetic material [11]. However, it has been reported that it has magnetism due to the deformation-induced martensitic transformation. Measurement of the Vickers hardness confirmed that the inner surface of stainless steel type 304 pipe became harder as the diameter decreased. Based on this change in hardness associated with the diameter, it was considered that stainless steel type 304 pipes would show a deformation-induced martensitic transformation by bending. Figure 9 shows the relationship between Vickers hardness and permeability. The permeability was $1.17 \mu$ for pipe $13 \mathrm{~mm}, 1.12 \mu$ for pipe $25 \mathrm{~mm}, 1.08 \mu$ for pipe $50 \mathrm{~mm}$, and $1.10 \mu$ for the plate. Although the permeability of pipe $50 \mathrm{~mm}$ was slightly lower than that of the plate, the order for pipe alone was pipe 13 $\mathrm{mm}>$ pipe $25 \mathrm{~mm}>$ pipe $50 \mathrm{~mm}$. Similar to the Vickers hardness and the maximum current density in the secondary active state, the permeability was consistent with the tendency to increase as the diameter decreased. Based on these results, the new method can be expected to be useful as an electrochemical method for evaluation of the deformation-induced martensitic transformation.

\section{Conclusions}

The results of this study can be summarized as follows.

1) Compared to plates, pipes are harder and tend to become harder and have greater permeability as the inner diameter decreases. This is thought to increase the amount of deformation-induced martensite and increase corrosion susceptibility.
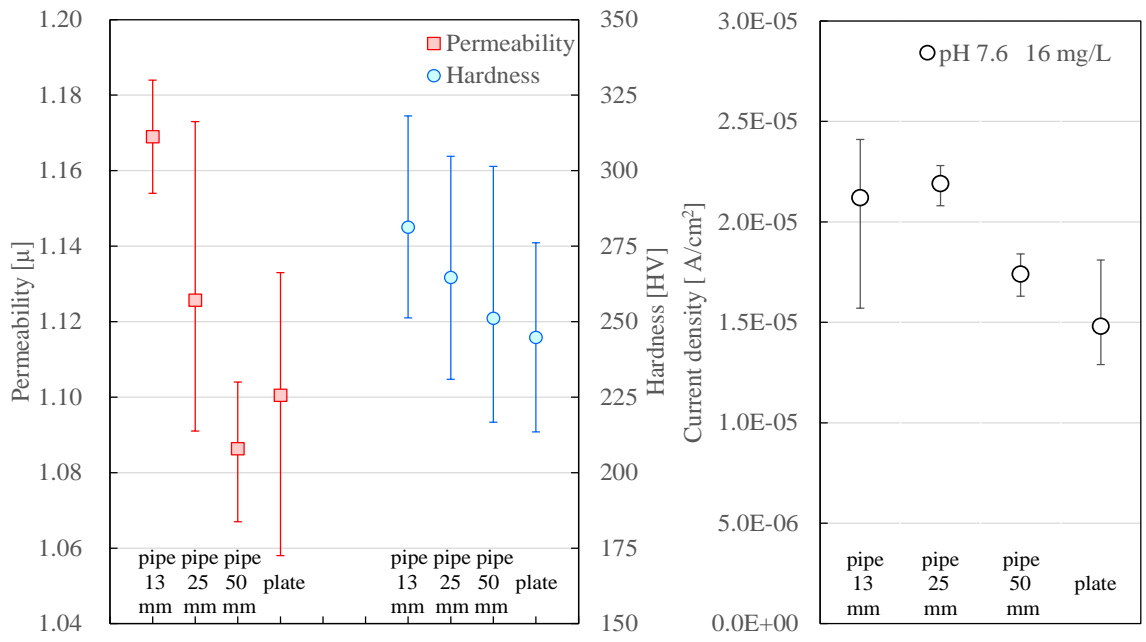

Figure 9. Comparison of material analysis results and secondary active state maximum corrosion current density. 
2) We found that the maximum corrosion current density in the secondary active state, which is the starting point of secondary passivation, appeared in the polarization curve measurement in tap water.

3) The peak of the secondary active current density was clearly seen as the potential sweep speed was increased. In addition, potential sweep speed dependence was observed in the corrosion susceptibility evaluation of deformation-induced martensite.

4) In comparison with acid treatment, it was considered that the formation of deformation-induced martensite occurred in the extreme surface layer.

5) The maximum corrosion current density in the secondary active state is expected to be useful as a new means of evaluating the deformation-induced martensitic transformation.

\section{Conflicts of Interest}

The authors declare no conflicts of interest regarding the publication of this paper.

\section{References}

[1] Tanaka, N., Sato, S., Watanabe, I., Yoshida, M., Yamada, Y. and Sakurada, O. (2017) Cases of Corrosion in Tap Water and Hot Water Supply Facilities of Stainless Steel Type 304 Pipes and Fundamental Study on Their Corrosion Resistance. Journal of the Surface Finishing Society of Japan, 68, 641-646.

[2] Tanaka, N., Sato, S., Watanabe, I., Yamada, Y. and Sakurada, O. (2018) Corrosion in Tap Water and Hot Water Supply Facilities of Stainless Steel Type 304 Pipes. Materials Sciences and Applications, 9, 68-80. https://doi.org/10.4236/msa.2018.91005

[3] Honnma, M., Morita, S. and Yamaya, K. (1965) The Welding Structure of 13\% Chromium Martensitic Stainless Steel and Its Rapid Heating and Cooling Behaviors. Journal of Japan Institute of Metals and Materials, 29, 1131-1136.

[4] Tamura, I. (1970) On the TRIP Steel. Journal of Japan Institute of Metals and Materials, 56, 429-445.

[5] Fiedler, H.C., Averbach, B.L. and Cohen, M. (1955) Tbo Effect of Deformation on the Martensite Transformation in Austonitio Steels. Transactions of the ASM, 47, 267.

[6] Buhler, H.E. and Schwenk, W. (1964) Einfluß der Gitterstruktur auf die Korrosion eines 18/10-Chrom-Nickel-Stahles. Werkstoffe und Korrosion, 15, 909-912. https://doi.org/10.1002/maco.19640151105

[7] Kamide, H. and Sugarwara, H. (1977) Role of Strain Induced Martensite on Stress Corrosion Cracking of 18-8 Stainless Steel in $\mathrm{H}_{2} \mathrm{SO}_{4}-\mathrm{NaCl}$ Solution. Journal of Japan Institute of Metals and Materials, 41, 528-534.

[8] Kamide, H. and Sugarwara, H. (1985) Relationship between the Dissolution Rate and the Dislocation Denstiy of $\alpha$-Martensite in $\mathrm{H}_{2} \mathrm{SO}_{4}-\mathrm{NaCl}$ Solution. BoushokuGijutsu, 34, 18-22.

[9] Copson, H.R. (1948) Corrosion Handbook. Wiley, New York.

[10] Sunada, S., Maesato, H., Yokoi, Y., Notoya, H., Sanuki, S. and Arai, K. (1990) Effect of Deformation-Induced Martensite on Pitting Corrosion of SUS304 Stainless Steel in $\mathrm{H}_{2} \mathrm{SO}_{4}-\mathrm{NaCl}$ Solution. Journal of Japan Institute of Metals and Materials, 54, 1078-1086. 
[11] Miura, K., Kobayashi, S., Kamada, Y., Onuki, Y. and Szpunar, J.A. (2014) Relationship between Morphology of Strain-Induced Martensite Phase and Magnetic Properties in Austenitic Stainless Steels. Journal of Japan Institute of Metals and Materials, 78, 375-380. 